\title{
Integrating supply chain and network analyses: The study of netchains
}

\author{
Sergio G. Lazzarini ${ }^{1,1}$ Fabio R. Chaddad ${ }^{2}$ \& Michael L. Cook ${ }^{3}$ \\ ${ }^{1}$ John M. Olin School of Business, Washington University, 1 Brookings Drive, Campus Box 1133, St. Louis, MO 63130-4899, \\ USA; Tel: 314-935-4538; Fax: 314-935-6359; E-Mail: LazzariniS@olin.wustl.edu \\ ${ }^{2}$ Agribusiness Research Institute, University of Missouri - Columbia, 138A Mumford Hall, Columbia, MO 65211, USA; E-mail: \\ frcbb6@mizzou.edu \\ ${ }^{3}$ Michael L. Cook, Agribusiness Research Institute, University of Missouri - Columbia, 125C Mumford Hall, Columbia, \\ MO 65211,USA; E-mail: CookML@missouri.edu
}

\begin{abstract}
This paper introduces the concept of netchain analysis. A netchain is a set of networks comprised of horizontal ties between firms within a particular industry or group, which are sequentially arranged based on vertical ties between firms in different layers. Netchain analysis interprets supply chain and network perspectives on inter-organisational collaboration with particular emphasis on the value creating and coordination mechanism sources. We posit that sources of value and coordination mechanisms correspond to particular and distinct types of interdependencies: pooled, sequential, and reciprocal. It is further argued that the recognition and accounting of these simultaneous interdependencies is crucial for a more advanced understanding of complex inter-organisational relations. The paper concludes with an analysis of a set of netchain configuration examples, including buyer-supplier relationships, information technology induced interorganization collaborations, and the introduction of the "macrohierarchy" organization structure.
\end{abstract}

Key words: network, supply chain, value chain, interdependence, cooperative strategy

\section{Introduction}

Supply chain and network analyses have been treated as two distinct strands in the literature on inter-organisational collaboration. Supply chains are defined as a set of sequential, vertically organized transactions representing successive stages of value creation. The literature on supply chain analysis (SCA) suggests vertical interdependencies require a systemic understanding of resource allocation and information flow between firms engaged in sequential stages of production (Christopher, 1998; Simchi-Levi et al., 2000). Value chain analysis (Porter, 1985), an approach describing a set of sequential activities creating value within firms, has been more recently extended to activities between firms (Barney, 1997).

Network analysis (NA), in turn, provides numerous tools to map the structure of inter-organisational relationships or "ties" based on the recognition that network structure constrains and at the same time is shaped by firms' actions (Granovetter, 1973; Burt, 1992; Nohria, 1992; Wasserman and Faust, 1994). Unlike SCA, NA is not particularly concerned with vertically organized ties, but rather with horizontal relationships between firms belonging to a particular industry or group (Powell, 1990).
Even though both SCA and NA stress the importance of interdependencies between multiple firms and how interorganisational relationships can be a source of competitive advantage (Dyer and Singh, 1998), the integration of their core concepts and analytical tools is still to be done $e^{2}$. Yet, it has been recognized that NA could benefit from a careful assessment of distinct types of ties (Nohria, 1992), whereas SCA could benefit from a network-based perspective of interfirm relations (Aitken, 1998; Stuart et al., 1998).

This paper attempts to fill this void in the literature by introducing the concept of netchain - a set of networks comprised of horizontal ties between firms within a particular industry or group, such that these networks (or layers) are sequentially arranged based on the vertical ties between firms in different layers (Figure 1). Netchain analysis explicitly differentiates between horizontal (transactions in the same layer) and vertical ties (transactions between layers), mapping how agents in each layer are related to each other and to agents in other layers.

For example, it is becoming increasingly important to evaluate not only how suppliers transact with a given buyer, but also how they interact between themselves to promote knowledge exchange (Stuart et al., 1998; Dyer and Nobeoka, 2000). SCA is not well equipped to discuss relations among

\footnotetext{
${ }^{1}$ We thank the helpful comments by two anonymous referees. All remaining errors and omissions are our own.

2 Some authors apply NA in contexts involving supply chains (Uzzi, 1997; Burt, 1992; Dyer and Nobeoka, 2000; Swaminathan et al., 2000), but the comparative and simultaneous assessment of vertical and horizontal relationships is not their main goal.
} 


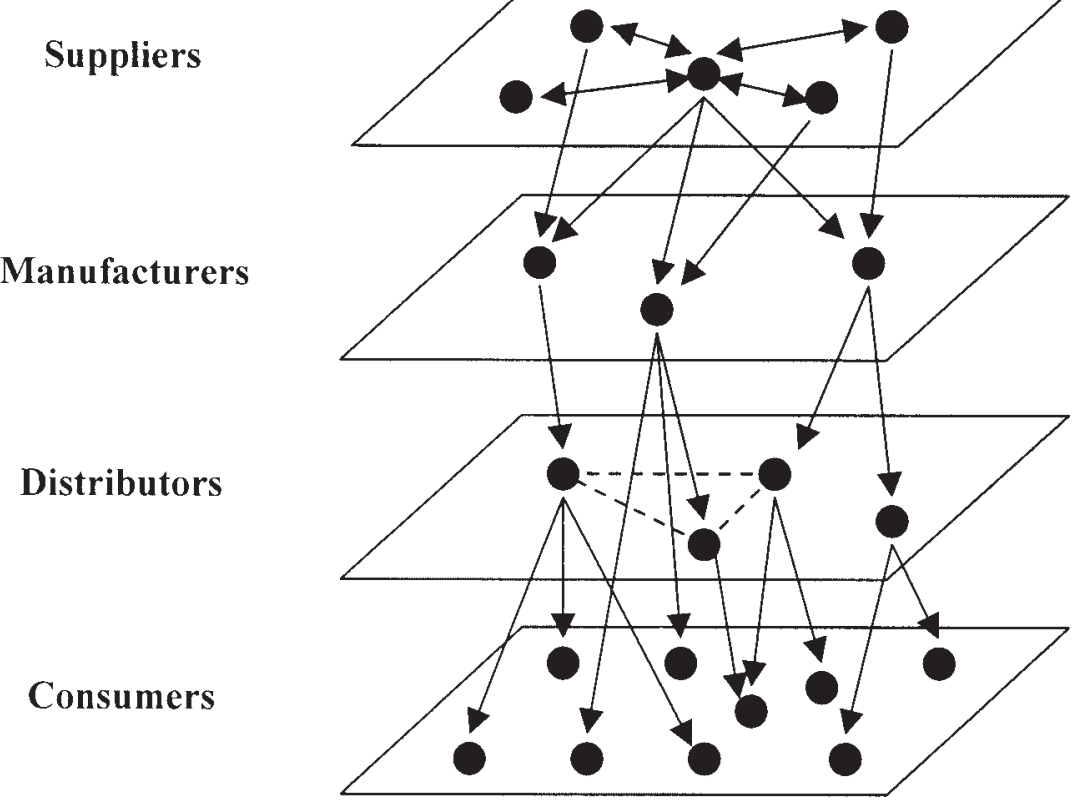

Figure 1. An example of a generic netchain.

suppliers because it focuses on elements related to vertical transactions, such as logistics management or the design of contractual arrangements between buyers and suppliers. On the other hand, even though NA provides elements to evaluate social attachments and knowledge transfer between firms, it is not particularly concerned with vertical ties. A combination of both perspectives may generate an enhanced general framework to assess inter-organisational collaboration.

More generally, we posit that such analytical integration is necessary because SCA and NA have focused on distinct types of interdependencies involved in inter-organisational collaboration. But if SCA and NA focus on particular types of interdependencies, what happens when several types of interdependence occur in a given inter-organisational setting? Stabell and Fjeldstad (1998) propose a framework considering organizational responses to distinct types of interdependence, but the authors treat chains and networks as alternative models. The same is true for Norman and Ramirez's (1993) distinction between value chain and value constellation, which resembles a network. The netchain approach, in contrast, is intended to integrate SCA and NA by recognizing that complex inter-organisational settings embody several types of interdependencies, which are associated with distinct sources of value - that is, strategic variables yielding economic rents - and coordination mechanisms involved in inter-organisational collaboration.
In order to discuss these issues in detail, the paper is organized as follows. In the next section, the main sources of value in inter-organisational relationships analysed by SCA and NA scholars are reviewed. In the third section, these sources of value are related to particular types of interdependencies and coordination mechanisms. The assessment of interdependencies is employed as an integrative element in netchain analysis because it avoids confining the study of inter-organisational collaboration to particular sources of value or coordination mechanisms. Subsequently, examples of netchain configurations are presented illustrating specific applications of netchain analysis. The netchain configurations section includes buyersupplier relationships, inter-organisational collaboration supported by information technology, and macrohierarchies, which are defined as patterns of ownership between organizations arranged in layers. Concluding remarks and suggestions for future research follow.

\section{Sources of value emanating from supply chain and network analyses}

In this section we identify the main contributions of supply chain analysis (SCA) and network analysis (NA) as they suggest alternative sources of value in the study of inter-firm collaboration. Sources of value are strategic variables yielding economic rents. They can be either associated with cost reduction, rent creation, or rent capture. The identification 
of these sources of value is crucial in assessing the contributions of SCA and NA and how both approaches can be integrated in a single analytical framework.

\section{Sources of value in supply chain analysis (SCA)}

SCA is a broadly defined field focusing on successive stages of value creation and capture in a vertically organized set of firms. Three core sources of value in SCA are identified: optimisation of production and operations, reduction of transaction costs, and appropriation of property rights.

\section{Optimisation of production and operations}

The concept of supply chain management has its roots in the 1960s concept of logistics management - a planning tool that seeks to develop a system-wide, integrated view of the firm. Subsequently, supply chain management extends the concept of logistics management to external integration of the firm. The supply chain is conceived as "a series of linked suppliers and customers" (Handfield and Nichols Jr., 1999, p. 2). It encompasses all activities associated with the flow and transportation of goods from the raw materials stage through the end user plus the concomitant information and financial flows. Supply chain management refers to the coordination and alignment of materials, financial, and information flows for all activities and processes involved in a supply chain (Simchi-Levi et al., 2000). Assuming the supply chain is managed as a single entity, supply chain optimisation models specify how chain performance is maximized by the optimal choice of a set of several production-related explanatory variables, such as number of stages in the supply chain, inventory levels, product differentiation, among others. Therefore, supply chain management models focus on the optimisation of production and operations as a key source of value. Supply chain performance includes quantitative cost-based and technical efficiency measures and qualitative indicators of customer responsiveness and satisfaction (Beamon, 1998).

\section{Reduction of transaction costs}

In addition to production optimisation, several scholars stress the importance of considering the optimisation of transactions based on Coase's (1937) insight that there are positive costs of using the market system, which later became known as transaction costs. These costs include ex ante search costs, bargaining and contracting costs, plus monitoring and enforcement costs, which occur in a postcontractual stage. Three distinct approaches in the literature analyse economic organization in a situation of positive transaction costs: agency theory, transaction cost economics, and measurement. In the agency literature, transaction costs emerge due to divergent interests and informational asymmetries between the parties to a contract (Jensen and Meckling, 1976). The design of incentive contracts can align the objectives of principals and agents and mitigate opportunistic behaviour, thereby increasing transactional efficiency (Sappington, 1991).

The second approach, transaction cost economics (TCE), is associated with Williamson's (1985) work. In contrast to agency theory, TCE emphasizes contract incompleteness, which hinders the possibility of crafting optimal incentive contracts. However, similar to agency theory, TCE considers the hazards of opportunistic behaviour, particularly when relationship-specific investments are involved (Klein et al., 1978). The major proposition of TCE is the presence of specific investments shifts organization away from markets to "hybrids" or, in the limit, vertical integration to mitigate potential hold-up problems (Williamson, 1985). Therefore, supply chain organization is a source of value when transactions are governed by efficient structures, from markets to hierarchies, aligned with attributes of the transactions along the chain (Zylbersztajn, 1996).

The third approach, measurement, focuses on the difficulty of measuring performance or product attributes in a transaction as a major explanatory variable determining governance choice (Barzel, 1982). When the performance or attributes of goods being transacted are imperfectly measured, pay-for-performance or pay-for-quality is problematic (Holmstrom and Milgrom, 1994). As a result, agents need to craft appropriate governance mechanisms to monitor and enforce contractual arrangements. Efforts to promote "traceability" of food products in supply chains in order to signal and guarantee certain product attributes to consumers, such as safety and origin, is an example.

\section{Value capture in weak appropriability regimes}

According to Teece (1986), innovators are not always able to capture the rents from innovation. Competitors or agents located in downstream or upstream stages in the supply chain may benefit from innovation when appropriability regimes are weak or they possess complementary assets. Weak appropriability occurs when technology is either easy to imitate or patent systems are not strongly enforced. Complementary assets, in turn, occur when new technology adoption depends on assets owned by other firms. If competitive advantage is shaped by the firm's ability to capture value from its resources (Teece et al., 1997; Teece, 1998), then the implications for supply chain management are evident: allocate investments through the chain in order to capture the gains from innovation, focusing on complementary assets. For example, biotechnology firms acquired complementary assets downstream in the agricultural chain (i.e., seed companies) to capture the value generated by knowledge-based assets through genetically 
modified seeds sold to farmers as those assets can be easily replicated by simply growing the seeds (Kalaitzandonakes and Bjornson, 1997).

\section{Sources of value in network analysis (NA)}

NA is a broad field commonly associated with sociology, but economists and strategy scholars have recently analysed network-based industries and have applied network concepts to explain economic organization and performance. Three core sources of value are emphasized in NA: social structure, learning, and network externalities.

\section{Social structure}

Social network approaches share a common emphasis on the role of social structure - i.e., interpersonal relationships and individual positions occupied by agents in a network - influencing individual or collective behaviour and performance. Granovetter (1985) uses the term embeddedness to explain how social relations affect the economic behaviour of agents and the institutional arrangements supporting transactions. The literature on social capital focuses on the role of "resources accruing to an individual or group by virtue of their location in the network of their more or less durable social relations" (Adler and Kwon, 1999, p. 4).

Different strands in social NA have assumed, however, divergent perspectives regarding the type of social relationship (or tie) and social structure that is more conducive to cooperative behaviour and superior performance. Some authors argue that dense networks with agents extensively connected with each other (Coleman, 1990) and strong ties defined as repeated, affective, relational exchanges (Nelson, 1989; Krackhardt, 1992) facilitate the emergence of trust, create social norms, and promote cooperation as a consequence. Dense networks can also create conditions for the emergence of intra-industry coalitions of firms that negotiate better terms of trade with firms in other industries or reduce competition within their own industry (Pfeffer and Nowak, 1976; Galaskiewicz, 1985; Lane and Bachmann, 1996). Cartels, trade associations, and cooperatives are examples of this phenomenon.

Other authors emphasize that sparse networks with several non-redundant contacts connected by structural holes ${ }^{3}$ (Burt, 1992) and weak ties defined by occasional, market-like exchanges (Granovetter, 1973) generate new information and diversity crucial to trigger innovation and create opportunities for network participants. This is important because strong ties and dense networks may induce "lock in" to idiosyncratic resources, which may be less valuable in the future due to technological or institutional ruptures (Grabher, 1993; Uzzi, 1997; Afuah, 2000). McEvily and Zaheer (1999) find a positive effect of structural holes on firm performance: firms that have non-redundant contacts outperform competing firms.

\section{Learning}

There are two fundamental types of learning processes with distinct consequences in terms of value creation. When autonomous agents or groups develop knowledge "locally" and specialize themselves in particular knowledge fields, learning tends to favour knowledge diversity. In this case, autonomous agents develop particular skills and "encapsulate" them in their interaction with other agents (Demsetz, 1988; Zenger and Poppo, 1999). Within a network perspective, knowledge diversity is beneficial because it generates positive externalities to multiple agents through knowledge spillovers, which enhance opportunities for innovation (Feldman and Audretsch, 1998; Kogut, 2000). Another type of learning involves systemic, joint efforts to create and refine a certain body of knowledge. This type of learning tends to induce knowledge co-specialization, i.e., skills that are dedicated to the agents participating in a given exchange (Zenger and Poppo, 1999). Co-specialization enables value creation through the combination of individual capabilities and the development of specific routines (Nelson and Winter, 1982; Kogut and Zander, 1992). However, co-specialization entails costs since it tends to reduce the range of new, valuable opportunities that can be exploited by agents and also their capacity to interpret external knowledge (Leonard-Barton, 1995). Rowley et al. (2000) offer a connection between learning and social structure and suggest that knowledge diversity is best served by weak ties, which tend to be conduits of new information, whereas co-specialization is facilitated by the existence of strong ties, which promote cooperation.

\section{Network externalities}

This source of value is extensively discussed in the literature on economic networks. Network externalities occur if the benefits to adopt some type of technology or contract increase with the expected number of adopters, thus inducing increasing returns to adoption (Arthur, 1989). Katz and Shapiro (1985) distinguish between direct and indirect network externalities. The direct type occurs when,

\footnotetext{
${ }^{3}$ For instance, if an agent $A$ is connected to a network of agents $N_{A}$ and $B$ is connected to another network $N_{B}$ in such a way that agents in $\mathrm{N}_{\mathrm{A}}$ and $\mathrm{N}_{\mathrm{B}}$ are not connected to each other, a tie between $\mathrm{A}$ and $\mathrm{B}$ would be non-redundant. This tie would span a structural hole between networks NA and NB. If, however, many agents in $\mathrm{N}_{\mathrm{A}}$ and $\mathrm{N}_{\mathrm{B}}$ have direct ties with each other, a tie between $\mathrm{A}$ and $\mathrm{B}$ would be redundant because they would be already connected with each other indirectly through their ties with agents in $N_{A}$ and $N_{B}$.
} 
for example, an agent adopting a trading technology, such as electronic commerce, increases the benefit for other agents to adopt that technology due to increased arbitrage opportunities or decreased trading costs (Domowitz, 1995; Economides, 1996). The indirect type occurs when there are complementarities among several technologies or exchange modes. Consider for example the benefits of purchasing a computer, which strongly depends on the supply of complementary products such as software shared by many users. In the presence of network externalities, there are benefits to promote interfirm coordination in order to capture the value generated as a result of network growth and avoid "lock in" to inferior technologies (Farrell and Saloner, 1985; Arthur, 1989) or contractual standards (Kahan and Klausner, 1997) that compete simultaneously over time.

\section{Conceptualising netchains}

In this section, it is argued that SCA and NA can be successfully integrated by identifying an underlying variable that explains why these approaches emphasize different facets of inter-organisational relationships. This variable is the nature of interdependence between two firms or agents, since transactions arranged as chains (emphasizing vertical ties) or networks (emphasizing horizontal ties) tend to differ with regard to the type of interdependence they generate (Stabell and Fjeldstad, 1998). Thompson's (1967) seminal categorization of organizational interdependencies is employed to contrast SCA and NA. ${ }^{4}$ The objective is not to refine Thompson's framework, but rather use it as a tool in analysing distinct types of inter-organisational interdependencies emanating from SCA and NA.

Thompson (1967) identifies three types of interdependence: pooled, sequential, and reciprocal. Pooled interdependence, the simplest type, occurs when each individual in a group makes a discrete, well-defined contribution to a given task. Sequential interdependence refers to serially structured tasks, when the activities of a firm or agent precede those of another. Finally, reciprocal interdependence - the most complex - involves simultaneous, ongoing relationships between parties in which each agent's input is dependent on the others' output and vice-versa (Figure 2). ${ }^{5}$

We posit that SCA has focused on sequential interdependencies, whereas NA has primarily dealt with either pooled or reciprocal interdependencies. In this section, this claim is supported in two ways. First, it is shown that the sources of value emphasized by SCA and NA correspond to distinct types of interdependencies. In addition, we discuss the coordination mechanisms commonly proposed by SCA and NA, which are associated with distinct interdependencies. This section concludes showing how netchain analysis can successfully integrate SCA and NA with a simultaneous assessment of all types of interdependencies.

\section{How distinct sources of value correspond to particular types of interdependence}

In the following discussion, the types of interdependence proposed by Thompson (1967) are outlined and related to the main sources of value emphasized by SCA and NA scholars.

\section{Pooled interdependence}

In this case, interdependence involves discrete or autonomous contributions by loosely coupled agents (Astley and Zajac, 1991). Pooled interdependence is more akin to independence because the relationship between agents is sparse and indirect (Van de Ven et al., 1976). Involving more or less anonymous agents, pooled interdependence

\footnotetext{
${ }^{4}$ Even though Thompson focuses on interdependencies within firms, other authors apply his framework in the context of inter-organisational collaboration (Borys and Jemison, 1989; Gulati and Singh, 1998).

${ }^{5}$ Van de Ven et al. (1976) propose a fourth type of interdependence: team work. The nature of interdependence is similar to the reciprocal case, but the authors characterize team interdependence as involving simultaneous actions. Reciprocal interdependence may involve a temporal lapse in the feedback process. But since we are not particularly concerned with temporal issues, teamwork is considered as a special case of reciprocal interdependence.
}

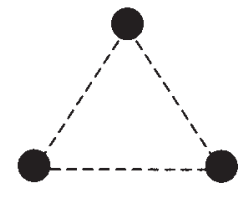

(a) Pooled

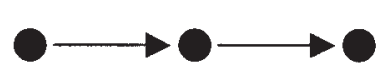

(b) Sequential

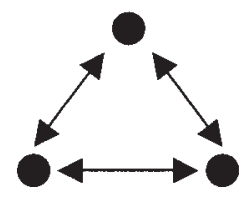

(c) Reciprocal

Figure 2. Representation of types of interdependence. 
has clearly a flavour of weak social ties and structural holes as "arbitrage" opportunities - e.g., job opportunities in a large network - are magnified. Additionally, due to its emphasis on autonomous and loosely coupled agents, pooled interdependence supports a situation of knowledge diversity, where specialized agents exchange knowledge directly or indirectly through products or services that embody such knowledge (Weick, 1976). Finally, since the connection between agents is sparse, it tends to be mediated by some underlying technology or organizational mode possibly with increasing returns to adoption. Thus, pooled interdependencies are likely to be associated with network externalities: the value of the network increases with its expected size (Stabell and Fjeldstad, 1998).

As discussed in the following section, Internet-based procurement mechanisms known as business-to-business (B2B) exchanges enable the connection between autonomous agents, thus creating pooled interdependencies between them. Some organizations - such as the chemical company Buckman and the World Bank - are stimulating knowledge sharing between their "internal specialists" located in different countries to solve practical problems. The underlying interdependence is pooled because those specialists interact infrequently and contribute with knowledge resulting from local, specialized experiences.

\section{Sequential interdependence}

This kind of interdependence involves direct relationships between agents ordered in a serial fashion: one agent's input is another agent's output. It is straightforward to note that this describes precisely a supply chain. The sources of value associated with buyer-supplier relationships usually stem from managing sequential interdependencies (Borys and Jemison, 1989). Inventory management, logistics, and the like attempt to optimise sequential production processes and operations, while efficient governance mechanisms attempt to reduce transaction costs and appropriate property rights in downstream or upstream stages in the chain, i.e., optimise sequential transactions.

The organization of transportation services is an evident example of sequential interdependence. Consider the international flow of cargo, correspondence and packages with sequential transactions from the origin to the destination, involving domestic trucking, domestic freight forwarding, international air transport, foreign freight forwarding, and forward trucking (Wada and Nickerson, 1998). The output of one stage (e.g., a parcel coming from another country through air transport) is clearly the input of another stage (e.g., freight forwarding). The value created from managing these transactions originates not only from logistics optimisation, but also from reductions in transaction costs, which are critical in the presence of local (e.g., an unusual destiny) and temporal specificities (e.g., customer requirement for fast delivery). In addition, the common practice of tracking parcels and cargo to inform clients about the exact position of those units in their route at a given moment attempts to solve measurement problems making use of information technology.

\section{Reciprocal interdependence}

Reciprocity in this kind of interdependence means that one agent's input is another agent's output and vice-versa. Consequently, agents are mutually dependent on the choices and actions made by each other. In this context, one should expect recurring, deep, intertwined relationships between agents, which suggests a situation of strong social ties and dense networks. Agents in this case are likely to be tightly coupled: the knowledge of one agent strongly depends on the knowledge of another, i.e., there is knowledge cospecialization.

A strategic alliance in which parties seek "to broaden or deepen their skills or to develop new skills jointly" is an example of inter-organisational collaboration involving reciprocal interdependence (Gulati and Singh, 1998, p. 797). In addition, groups characterized by shared culture, identity, and norms, such as regional clusters of small firms and close-knit groups, create reciprocal interdependencies through the development of dense networks. Japanese supplier networks, which are discussed in the next section, are also an example of inter-organisational relations showing reciprocal interdependencies.

Pooled and reciprocal interdependencies involve sources of value that are commonly dealt with in NA. And since serially ordered ties describe a chain organization, it is not surprising that SCA focuses on sources of value associated with sequential interdependencies. It is important to notice that the sources of value that are related to each type of interdependence are main sources of value. It is possible that, for example, strong social ties and dense networks facilitate cooperation and decrease transaction costs as a result (Ouchi, 1980). But transaction cost minimization is not the unique reason for those relationships since they can involve value creation - for example, joint knowledge development - and other outcomes that transcend the simple desire to reduce transaction costs (Zajac and Olsen, 1993; Dyer, 1997).

\section{How interdependencies correspond to distinct coordination mechanisms}

Another way to demonstrate that NA and SCA focus on distinct types of interdependencies is to review the main coordination mechanisms proposed or implied by each approach. Thompson (1967) suggests that each type of 
interdependence should be handled with particular coordination modes. These coordination modes include standardization, plan, and mutual adjustment.

\section{Standardization}

According to Thompson (1967), pooled interdependencies are well managed by standardized rules and shared mechanisms to orchestrate transactions. The economic approach to networks argues that compatibility between products and components, usually achieved through a standardized technological platform, is a key element to capture network externalities. Thus, firms may coordinate product design to generate increasing returns to adoption (Farrell and Saloner, 1985; Katz and Shapiro, 1985). Another example of coordination through standardization is a financial exchange, where contracts and negotiation rules are standardized in such a way to allow trade at low cost and therefore attract many anonymous agents (Telser and Higginbotham, 1977; Domowitz, 1995; Economides, 1996). In section 4 , it is shown how the Internet enables the emergence of standardized codes that support information transfer between firms and pooled interdependencies. Also, firms encouraging knowledge sharing between internal specialists depend on standardized mechanisms through the Internet to form discussion groups and retrieve information from sparsely connected individuals.

\section{Plan}

Sequential interdependencies require coordination by a plan, involving "the establishment of schedules for the interdependent units by which their actions may then be governed" (Thompson, 1967, p. 56). This type of coordination denotes discretionary actions by a coordinating agent, who plans the flow of products and information, and promotes adaptation to changing internal or external conditions. ${ }^{6}$ Indeed, the literature on supply chain management has called for managerial discretion in order to optimise production processes and operations (Beamon, 1998), or align efficient governance mechanisms to sequential transactions (Zylbersztajn and Farina, 1999). For instance, the management of courier services requires a central planner, such as Federal Express and DHL, who not only defines schedules, routes and transport modes, but also contractual arrangements to coordinate sequential transportation stages from the sender to the recipient (Wada and Nickerson, 1998).

\section{Mutual adjustment}

Thompson (1967) claims that reciprocal interdependencies require the transmission of new information through mutual feedback processes, which he calls "mutual adjustment." Instead of a central planner, mutual adjustment implies joint problem solving and decision making. As a result, personal or group-based coordination mechanisms become necessary (Van de Ven et al., 1976). Perhaps not surprisingly, social network scholars commonly discuss this type of coordination. As Powell (1990, p. 303) remarks, "in network modes of resource allocation, transactions occur neither through discrete exchanges nor by administrative fiat, but through networks of individuals engaged in reciprocal, preferential, mutually supportive actions." According to social network scholars, the formation of inter-organisational relations tends to be emergent rather than premeditated, where feedback from past transactions in the network is a crucial element. Past transactions are likely to reveal information about performance and partners' conduct (Gulati and Gargiulo, 1999), foster learning (Powell et al., 1996), and reinforce social norms and informal sanctioning mechanisms (Granovetter, 1985).

In sum, SCA focuses on coordination mechanisms involving some sort of plan or discretionary managerial action, which according to Thompson (1967) corresponds to sequential interdependence. NA, in turn, emphasizes either standardization or mutual adjustments, which are appropriate coordination mechanisms to deal with pooled and reciprocal interdependencies respectively.

\section{Netchain analysis: Assessing all types of interdependencies}

Figure 3 summarizes the preceding discussion and presents the sources of value and coordination mechanisms corresponding to each type of interdependence, showing that NA focuses on pooled and reciprocal interdependencies, whereas SCA emphasizes sequential interdependencies. We propose that one way to integrate SCA and NA is to consider simultaneously all types of interdependencies that occur in a given inter-organisational setting.

This simultaneous assessment is the core of netchain analysis. Instead of focusing on certain sources of value and/or coordination mechanisms given a certain type of interdependence, the netchain approach begins by recognizing the relevant interdependencies involved in inter-organisational collaboration. The concept of netchain

\footnotetext{
${ }^{6}$ Victor and Blackburn (1987) refine Thompson's model by considering conflicts of interest created by interdependencies. When these conflicts are high, they argue a "chain of command" will emerge. Note, however, that these conflicts tend to be critical in the case of sequential interdependencies because one party's input is an output of the other: conflicts over prices, for example, tend to be acute. Thus, the prediction is the same: coordination by plan (command) will emerge in the case of sequential interdependencies.
} 
- Optimization of production and operations

- Reduction of transaction costs

- Value capture in weak appropriability regimes

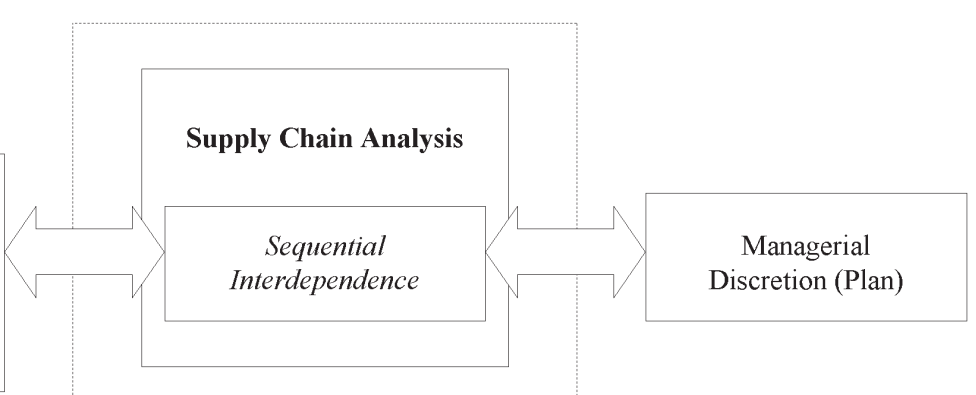

- Weak social ties and structural roles

- Diversity of knowledge

- Network externalities

- Strong social ties and dense networks

- Co-specialization of knowledge

Sources of Value

Netchain Analysis

Process

Standardization

Mutual

Adjustment

Coordination

Mechanisms

Figure 3. An overview of netchain analysis.

integrates SCA and NA precisely because it allows for a simultaneous account of all types of interdependencies, in addition to the sources of value and coordination mechanisms associated with them. If, for example, we confine ourselves to the analysis of sequential (vertical) transactions, several sources of value and coordination mechanisms associated with pooled or reciprocal interdependencies are likely to be neglected. In other words, netchain analysis does not take interfirm interdependence as given, but rather includes it as a key variable in the model. In the next section, netchain analysis is applied to specific empirical cases. Before proceeding, two important remarks are in order. First, it was previously mentioned that SCA and NA focus on vertical and horizontal transactions respectively. Even though the graphical representation of a netchain proposes a combined assessment of horizontal and vertical ties, the crucial aspect to qualify a given tie in a netchain is the nature of interdependence between agents. For example, vertical transactions typically exhibit sequential interdependencies (Pennings, 1981), but they can also embody reciprocal elements such as strong social attachments and knowledge co-specialization. At first glance, this may appear to be inconsistent with the fact that vertical ties exhibit sequential interdependence. Yet Thompson (1967, p.55) proposes a hierarchical relationship between interdependencies by arguing, "all organizations have pooled interdependencies; more complicated organizations have sequential as well as pooled; and the most complex have reciprocal, sequential, and pooled."

Second, netchain analysis abstracts from issues regarding firm boundaries. Gulati and Singh (1998) offer a theory to explain the choice between equity and non-equity strategic alliances based on Thompson's notion of interdependence. We believe, however, that interdependencies do not fully determine firm boundaries. For example, reciprocal interdependencies can be carried out internally by the firm or externally through alliances or social mechanisms. Paraphrasing Jensen and Meckling's (1976) conceptualisation of the firm as a nexus of contracts, ${ }^{7}$ which avoids the analytical demarcation of firm boundaries, a

${ }^{7}$ Zylbersztajn and Farina (1999) use the same term to characterize chain organization. 
netchain is conceptualised as a nexus of interdependencies. In other words, the netchain approach analyses the nature of interdependencies involved in a given setting, taking firm boundaries as exogenous. The study of endogenous firm boundaries within a netchain would be an important extension of this work.

\section{Some netchain configurations}

In this section, the concepts developed in the previous section are applied to the analysis of particular cases involving distinct netchain configurations. These cases serve to demonstrate the applicability of the concept, not to support specific theoretical claims, and indicate necessary steps toward the future use and refinement of netchain analysis.

\section{Buyer-supplier relationships}

Traditional approaches to the management of buyer-supplier relationships have focused on the design and maintenance of vertical, serially ordered relations between a buyer and its suppliers individually. The analysis of "tiered" supplier structures is an example, where attention is paid to the choice of certain top-tier suppliers who supply critical resources to the buyer and are responsible for product and service flow from lower-tier suppliers (Asanuma, 1989). This view, however, focuses solely on sequential interdependencies between buyers and suppliers. Some authors challenge this view and suggest network-based interactions between suppliers are equally important (Stuart et al., 1998).

Japanese manufacturing is a classic example of horizontal relations, where suppliers are organized through associations (kyoryokukai) aimed at promoting knowledge exchange and socialization (Nishiguchi, 1994; Dyer and Nobeoka, 2000). Contrary to common sense, Japanese supplier associations emerged due to a governmental initiative to promote cooperation, even though in some cases - such as in Toyota's association - they were reinforced by private initiatives (Nishiguchi, 1994). Supplier associations have also been replicated in other countries, such as in Toyota's plants in the U.S. (Holmstrom and Roberts, 1998; Dyer and Nobeoka, 2000) and Australia (Langfield-Smith and Greenwood, 1998).

However, network-based relations between suppliers are not only restricted to supplier associations. Dyer and Nobeoka's (2000) empirical analysis of Toyota's supplier networks in both Japan and the U.S. show that practices other than associations are used to foster exchange of knowledge and socialization between suppliers. Consulting and problem-solving teams are organized by Toyota in order to pursue quality- and productivity-enhancing solutions to several production problems. A key element is the existence of voluntary learning teams (jishuken), involving groups of suppliers exchanging knowledge between them in a more practical manner. These teams are heavily valued by suppliers as a way to promote improvements in production processes, cut costs, or create new solutions based on sharing individual experiences.

As a common attribute of Toyota's supplier networks, Dyer and Nobeoka (2000, p. 350) remark that they are "highly interconnected, strong-ties network [with] multiple pathways among members effectively eliminating most structural holes." Thus, one crucial source of value in this model refers to dense relationships with strong ties. Additionally, the authors point out suppliers in these networks "have developed reciprocal obligations for sharing knowledge with other members in the network" (p. 363), thus suggesting knowledge co-specialization. One natural question in this context is how to avoid the shortcomings of dense networks, strong ties and knowledge cospecialization, such as a lower potential to innovate and interpret external knowledge. Dyer and Nobeoka (2000, p. 365) note that in this model "there is the risk that the diversity of knowledge that resides in the network will diminish over time." Toyota has responded to this risk by employing several tactics such as changing the composition of learning groups from time to time and searching for "best practices" in other contexts through committees organized by supplier associations.

Thus, supply chains with supplier networks involve typically two types of interdependencies: one sequential, between assemblers and their suppliers, associated with vertical ties; and another reciprocal, among suppliers, associated with horizontal ties. This basic netchain configuration is depicted in Figure 4: single arrows represent sequential interdependencies, while double arrows represent reciprocal interdependencies. Sequential interdependencies are managed by discretionary, planned actions by a central firm, such as Toyota. Reciprocal interdependencies, in turn, are coordinated through mutual adjustments - in Toyota's case, through feedback from each other's experience in the

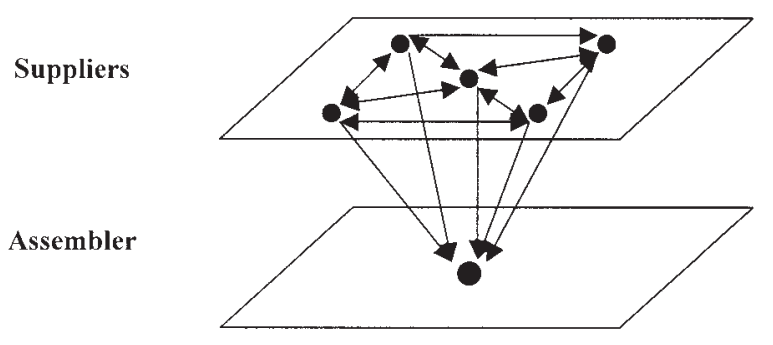

Figure 4. Buyer-supplier relationships. 
supplier network. Even though Toyota coordinates to some degree the formation and maintenance of these supplier practices, voluntary learning teams are considered to be more effective in knowledge sharing. Instead of relying on knowledge imposed by a given buyer, this new model of buyer-supplier relationships emphasizes systemic learning and collective decisions within supplier networks (Stuart et al., 1998).

Notice that traditional SCA, focusing on vertical ties embodying sequential interdependencies, is unable to assess the sources of value that emanate from reciprocal interdependencies between suppliers, such as strong social ties and knowledge co-specialization. On the other hand, NA tends to neglect the importance and distinctive nature of vertical ties given the sequential interdependencies they generate. The netchain approach allows for a more complete picture of this inter-organisational setting, considering simultaneously the existence of sequential and reciprocal interdependencies, which are associated with distinct sources of value and coordination mechanisms.

\section{IT-enabled inter-organisational collaboration}

To understand how information technology (IT) supports inter-organisational collaboration in the context of a netchain, two IT innovations that induced distinct types of interdependence are contrasted in this section: closed electronic data interchange (EDI) systems, and Internetbased procurement.

EDI involves computer-to-computer exchange of information between buyers and suppliers (Holland et al., 1992; Marcussen, 1996). Early (or closed) EDI systems, which gained momentum especially in the 1990s, are associated with specifically negotiated codes and a proprietary, or closed, electronic architecture to transfer information. According to Holland et al. (1992, p. 544), early EDI systems are "used to encourage close trading relationships with a smaller number of suppliers." Within this perspective, early EDI systems involve investments by both parties in private computer connections and training, implying a closed architecture of connection and agreements specifying information transfer codes (Brousseau, 1994; Dearing, 1995). Many authors document two main advantages of early EDI systems: a potential reduction of transaction costs, including procurement and monitoring expenses (Brousseau, 1994; Dearing, 1995) and the optimisation of production through information sharing (Holland et al., 1992), shortened lead times (Dearing, 1995; Niederman, 1998), inventory reduction and increased product quality (Kekre and Mukhopadhyay, 1992). These sources of value are strongly associated with sequential interdependencies. Additionally, private communication systems are commonly implemented by a systems initiator (e.g., a buyer), "who deploys a proprietary [system] to expand the scope of hierarchical control" to a particular firm (e.g., a supplier), "which exercises the choice between accepting or rejecting" the new system (Zaheer and Venkatraman, 1994, p. 551). This has clearly a flavour of plan-based coordination. ${ }^{8}$

In contrast, the Internet allows for standardized transacting procedures shared by many agents and an open architecture of connection, the World Wide Web (Kambil et al., 1999; Croom, 2000). Internet procurement has emerged with the help of "orchestrated" markets called business-to-business (B2B) exchanges. B2B exchanges create an electronic marketplace with low-cost entry and standardized transactional procedures - e.g., the display of buyer's specifications, bidding procedures, market clearing, safeguarding, and so on. Interdependencies are pooled because the bidding process is impersonal and carried out by autonomous suppliers. As such, network externalities constitute the main source of value associated with Internetbased procurement. Namely, the benefits of this governance mechanism increase with the number of suppliers adhering to the same standard because an alternative supplier that can closely match buyer's specifications will likely participate in the bidding process (Lazzarini and Nickerson, 2000). This is the case in $\mathrm{B} 2 \mathrm{~B}$ exchanges involving price negotiation instead of "catalogs" with posted prices, since in the first case Internet procurement reduces transaction costs and increases competition in the procurement process (Kaplan and Sawhney, 2000).

A remarkable example of a B2B exchange is FreeMarkets Online, which has generated approximate savings of 15 percent in the procurement costs of its clients mainly due to lower acquisition prices (Rangan, 1998). Glen Meakem, one of the firm's co-founders, points out that his company "introduces buyers to aggressive, world-class suppliers that they may not have known about before" (Rangan, 1998, p. 10). As another example, the British retailer Safeway reduced the cost of connecting its web of suppliers through the Internet to "only a few thousand dollars against several million for EDI. [Thus,] the supermarket can easily increase

8 It is also possible that the strong attachment between firms brought by early EDI systems also induced reciprocal interdependencies in the long run. As Zaheer and Venkatraman (1994, p. 554) hypothesize, "trust is enhanced through greater use of communication between [the parties] under conditions of dedicated electronic interfacing." Also, the presence of trust increases the willingness of the parties to invest in expensive, non-redeployable electronic connections. For simplicity, the focus is placed on the sequential nature of interdependencies emphasized by early EDI systems. 
the number of its suppliers, giving it more choice and better prices" (The Economist, 1999, p. 17). This suggests that the advent of Internet-based procurement is creating pooled interdependencies between a large number of loosely coupled agents, where standardization of connection and transacting procedures is the key coordination mechanism enabling low cost supplier participation.

Netchain configurations representing these contrasting ITenabled inter-organisational structures are presented in figure 5. The structure of early EDI-based procurement is presented in figure $5 \mathrm{a}$, depicting idiosyncratic, sequential transactions between a buyer and a supplier. The structure of Internet-based procurement is depicted in figure $5 b$, with two basic differences from the former case. First, there is a new layer occupied by an "infomediary," such as a B2B exchange, which aggregates many buyers and many suppliers with an open architecture of connection and standardized transacting procedures (Hagel III and Singer, 1999). Second, this infomediary induces horizontal, pooled interdependencies among buyers and among suppliers depicted in figure $5 \mathrm{~b}$ as dashed lines - using standardization as a coordination mechanism. ${ }^{9}$ The netchain approach provides a more complete framework to contrast these two
IT-based models because it recognizes the distinct types of interdependencies involved in each case, which lead to distinct sources of value and coordination mechanisms.

\section{Macrohierarchies}

Macrohierarchies are hierarchies involving organizations instead of agents within organizations - that jointly coordinate some of their activities through multiple layers of ownership. One particular example of macrohierarchy is discussed: farmer cooperatives organized in a multi-layered fashion, which is known as the federated structure.

In a federated agricultural cooperative, patrons are members of a local cooperative, which in turn is a member of a regional cooperative. ${ }^{10}$ Regional cooperatives themselves may also decide to form an inter-regional cooperative. ${ }^{11}$ As a result, a federated cooperative is structured by means of sequential layers of ownership (Figure 6). In addition, cooperatives are characterized by restricted residual claims, i.e., they are owned and controlled by patrons (Fama and Jensen, 1983). Consequently, the vertical ties between subsequent layers of a federated cooperative structure entail both a transaction and an ownership relationship.

\footnotetext{
${ }^{9}$ The single arrows denoting sequential interdependencies in Figure $5 \mathrm{~b}$ refer to the flow of orders, not necessarily the physical flow of products. Indeed, many B2B exchanges do not get involved in storage or physical handling of products; they go directly from a particular supplier to a particular buyer.

${ }^{10}$ A patron is defined as any person who transact with a firm. For example, a farmer in an agricultural cooperative, a depositor in a savings and loan mutual association, a borrower in a credit cooperative, or a buyer in a consumer cooperative.

${ }^{11}$ Contrasting to this federated or multi-layered structure, patrons are direct members of a regional cooperative in a centralized structure.
}

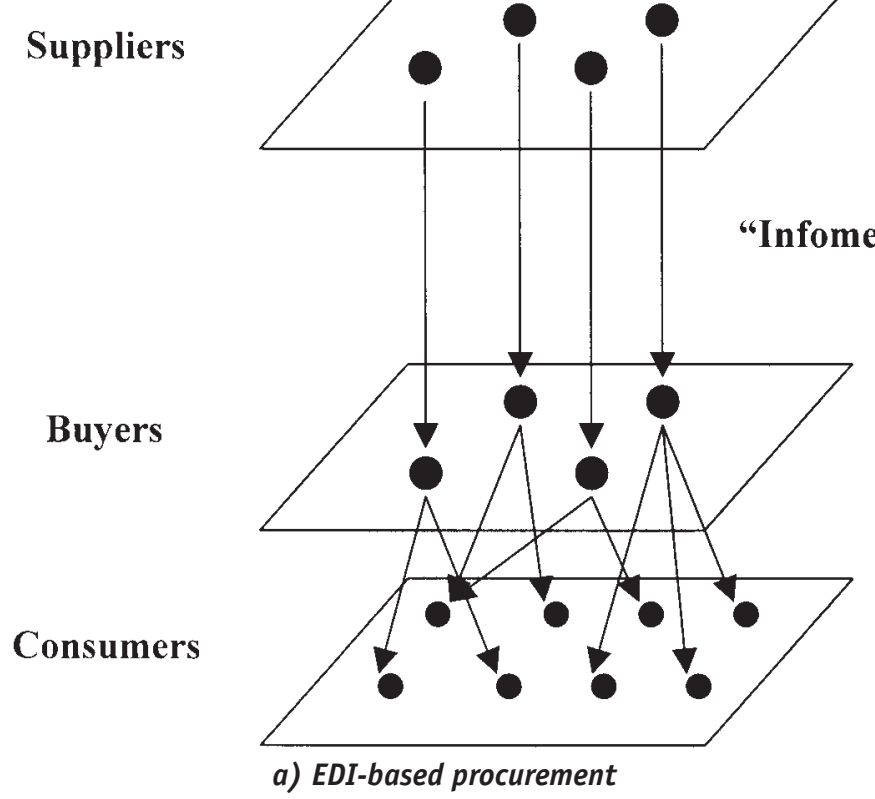

Figure 5. inter-organisational collaboration induced by information technology.

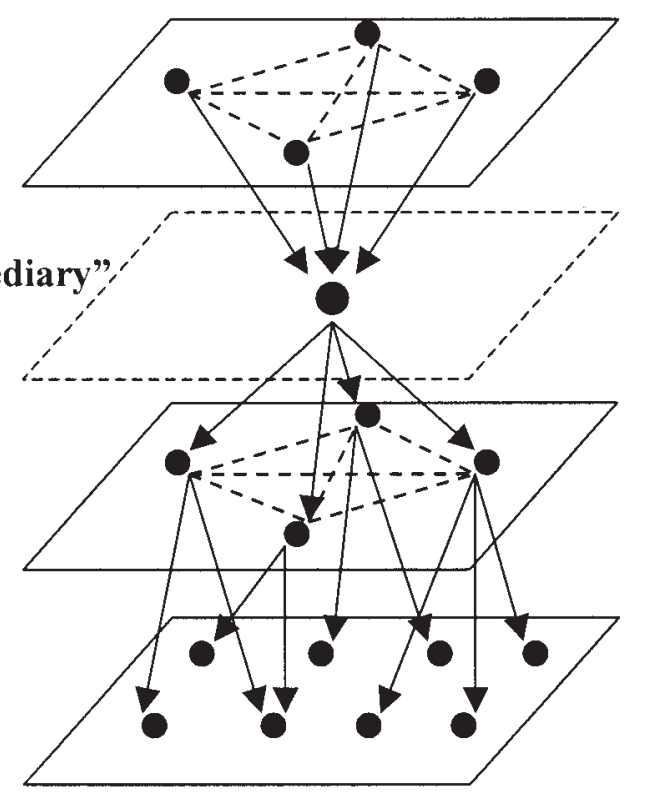

b) internet-based procurement 
The assignment of ownership in a cooperative to its patrons is often explained as a transaction cost minimization strategy, which is a source of value associated with sequential interdependencies. When farmers own - and, therefore, control - an agricultural cooperative they avoid potential hold-up situations arising from location and temporal asset specificity. For example, by forming a cooperative, dairy farmers can invest in equipment for storage and processing, thereby avoiding downstream pressures to reduce prices given the perishable nature of their product. Additionally, market contracting is costly when the firm has better information than its patrons (or vice-versa). In case a firm knows more about the quality of the product it sells, it has an incentive to deliver a lower-quality product than originally promised. In this case, customer ownership reduces the firm's incentive to exploit its information advantage. Hansmann (1996) explains the formation of consumer and agricultural supply cooperatives on the basis of measurement problems of this sort.

Notice that there are multiple sequential interdependencies in many farmer cooperatives, since in one occasion farmers sell their output to the cooperative (e.g., milk), while in other occasions they acquire production inputs from the cooperative (e.g., seeds and fertilizers). These interdependencies are not properly classified as reciprocal because these transactions are not necessarily carried out together, except in some cases where the cooperative "bundles" services (e.g., product acquisition and technical support) and products (e.g., farm inputs). As discussed previously, the contractual hazards created by these sequential transactions determine ownership by farmers, which then acquire rights to control (or "plan") the allocation of resources through successive stages of the supply chain.
In addition to these sequential interdependencies, federated cooperative structures are also characterized by pooled and/or reciprocal interdependencies among members (or cooperatives) within the same horizontal layer. For example, individual members within the same layer keep their decision-making autonomy, but pool their financial and productive resources to create a higher-level structure to develop related businesses, therefore characterizing a pooled interdependence. This higher-level structure defines common, standardized rules to commercialise products, purchase inputs, transfer information, and divide the residual claims among members.

Additionally, Bonus (1986) refers to the local cooperative as a "social group" with an "esprit de corps." The formation of reciprocal interdependencies among farmers in local cooperatives is explained as a consequence of intimate personal knowledge and strong social ties, a distinguishing characteristic of rural communities. In those circumstances, members are likely to employ joint decision making and problem solving to coordinate their activities - i.e., mutual adjustments. As a result, the transactional and ownership components of the vertical ties are embedded in a network of personal relationships among members. These social attachments may foster the emergence of trust, which tends to neutralize potential internal conflicts and opportunistic behaviour. In other words, reciprocal interdependencies may positively affect vertical transactions between layers. According to Staatz (1987), some cooperatives have an identifiable base of member-patrons who are more inclined to reveal strategic, proprietary information to their cooperative (and vice-versa). Farmers can also be members of more than one local cooperative - such as in the case of farmer $F$ in figure 6 - which tends to facilitate the joint

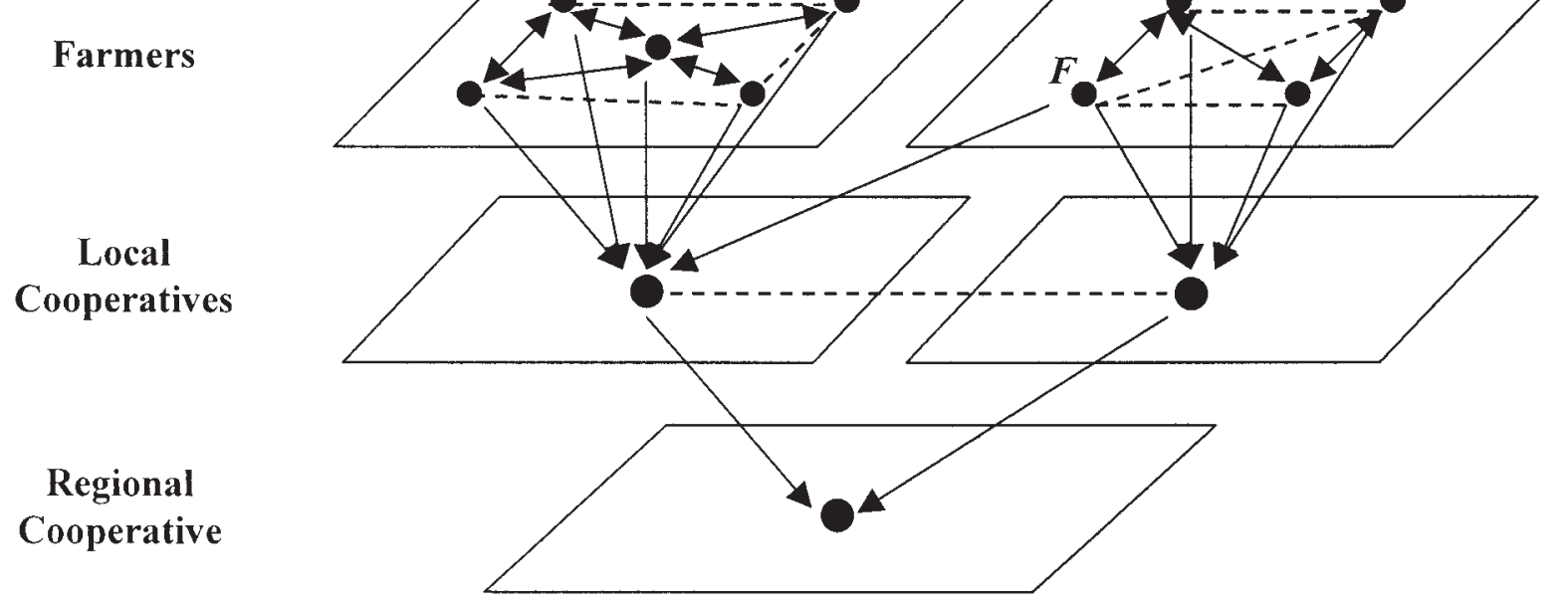

Figure 6. An example of macrohierarchy - The federated cooperative structure. 
coordination of local cooperatives belonging to a higherlevel (regional) cooperative.

Therefore, the analysis of vertical patterns of ownership between organizations should also consider the nature of the interdependencies involving firms within the same layer, which tend to be either pooled or reciprocal. Layers that are more in the base of the hierarchical structure are more likely to present a higher proportion of reciprocal interdependencies due to social interactions among individual members. Nevertheless, the concept of macrohierarchy based on the netchain framework helps to accomplish the simultaneous assessment of these interdependencies and how they influence the nature of ownership ties.

\section{Conclusions}

SCA and NA are important, yet analytically disconnected approaches to study inter-organisational collaboration because they focus on different types of interdependencies. Netchain analysis attempts to integrate SCA and NA by considering simultaneously all types of inter-organisational interdependencies, which correspond to distinct sources of value and coordination mechanisms. This is important for both positive and normative reasons.

In a positive sense, the simultaneous account of distinct interdependencies is crucial to the analysis of complex interorganisational relations, instead of assuming that the world is arranged either vertically or horizontally. If only one particular type of interdependence is focused, crucial elements involving other types of interdependence are likely to be missed, which may be responsible for a substantial part of the rent creation in the system. Therefore, the netchain perspective posits that the assessment of interdependencies in a given inter-organisational setting is the first analytical step.

In a normative sense, the netchain approach can reconcile the somewhat diverging ways of how SCA and NA inform business policy. The literature on supply chain management emphasizes the role of managerial discretion to coordinate the flow of products, information and decisions in supply chains. Thus, according to SCA, managers are well advised to actively coordinate the chain within which their firms are located to minimize transaction costs, optimise production flows, or capture value along the chain. inter- organisational collaboration in the NA literature, however, tends to be portrayed as more autonomous and emergent. Following this perspective, managers should develop social ties where activities are mutually adjusted instead of planned and at the same time pursue flexibility to position their firms in valuable networks to benefit from new information and knowledge diversity.

From the point of view of netchain analysis, all business policy recommendations are valid depending on the type of inter-organisational interdependence they are addressing. Therefore, it is clear that normative decisions should first involve considerations about interdependencies. As Levinthal and Warglien (1999, p. 343) put it, the performance of complex systems should be enhanced through "a shift from designing on the basis of a given set of interdependencies to designing by manipulating the set of interdependencies." For instance, the first crucial decision faced by an entrepreneur who wants to invest in a distribution system is not contract negotiation, logistics design and other coordinating activities. The entrepreneur must first define the type of interdependence that the distribution system will embody: he or she can either connect several suppliers and customers through a B2B exchange or manage the flow of specialty products from a restricted set of suppliers to a restricted set of buyers. For this reason, the netchain perspective also insists that the design of interdependencies is the first step in the formulation of interorganisational strategies.

Several lines of future research can expand and improve the framework proposed herein. It would be useful to develop quantitative measures for the assessment of a firm's position in a netchain and distinguish between the different types of interdependencies involved in the system. The vast literature on social NA can contribute to the development of those measures ${ }^{12}$. Another possible line of research could involve an endogenous demarcation of firm boundaries in a netchain. In other words, in how many layers should a firm be present (the vertical scope of the firm), and what should be the extent of its participation in each layer (the horizontal scope)? A dynamic analysis of the evolution of netchains, in particular with regard to possible changes in the interdependencies between agents when they transact over time, is also needed. In addition, it is important to include the role of "chain service providers," such as financial

\footnotetext{
12 Blockmodeling is a tool in social NA that allows for the aggregation of agents into sectors; the network of sectors is analyzed instead of the network of agents. Some authors have used this technique to model vertical relationships (Madhavan et al., 1998). However, much intra- and inter-layer information is not captured by this analysis. As Wasserman and Faust (1994) remark, a blockmodel is "a model, or a hypothesis about a multi-relational network. It presents general features of the network, such as the ties between positions, rather than information about individual actors" (p. 395, emphasis in the original). In contrast, the netchain approach attempts to model specifically how each agent in a layer is related to agents in other layers.
} 
organizations and logistics firms, which are not direct participants in a netchain but contribute in the process of value creation by interacting with several layers. ${ }^{13}$ Finally, netchain analysis could simultaneously assess more than one netchain at a time in order to evaluate competition between alternative netchains. In many industries, firms are developing competing networks (Gomes-Casseres, 1994) that are actually competing netchains. For instance, several airlines are forming alliances to expand bookings on international markets, share computer reservation systems, explore marketing practices such as frequent flyer programs, and in some cases develop joint procurement operations. It is clear these alliances should not only be defined in terms of the (horizontal) ties between airlines, but also in terms of their ties with agents on upstream (aerospace manufacturers, input suppliers) and downstream layers (travel agencies, web sites and customers). The relative performance of competing netchains depends crucially on how their underlying interdependencies deliver superior sources of value, and how firms employ appropriate coordination mechanism to cope with those interdependencies.

\section{References}

Adler, P.S. and S.W. Kwon, 1999. Social capital: the good, the bad, and the ugly. Working Paper available at http://www.ssrn.com

Afuah, A., 2000. How much do your competitors' capabilities matter in the face of technological change? Strategic Management Journal 21, 387-404.

Aitken, J., 1998. Supply Chain Integration within the Context of a Supplier Association. Unpublished Ph.D. Thesis, Cranfield University.

Arthur, W.B., 1989. Competing technologies, increasing returns, and lock-in by historical events. The Economic Journal 99, 116-31.

Asanuma, B., 1989. Manufacturer-supplier relationships in Japan and the concept of relation-specific skill. Journal of the Japanese and International Economies 3, 1-30.

Astley, W.G. and E.J. Zajac, 1991. Intraorganizational power and organizational design: reconciling rational and coalitional models of organization. Organization Science 2, 399-411.

Barney, J.B., 1997. Gaining and Sustaining Competitive Advantage. Reading, Addison-Wesley.

Barzel, Y., 1982. Measurement cost and the organization of markets. Journal of Law and Economics 25, 27-48.

Beamon, B.M., 1998. Supply chain design and analysis: models and methods. International Journal of Production Economics 55, 281-94.

\footnotetext{
${ }^{13}$ We thank one anonymous referee for this important remark.
}

Bonus, H., 1986. The cooperative association as a business enterprise: a study in the economics of transactions. Journal of Institutional and Theoretical Economics 142, 310-39.

Borys, B. and D.B. Jemison, 1989. Hybrid arrangements as strategy alliances: theoretical issues in organizational combinations. Academy of Management Review 14, 234-49.

Brousseau, E., 1994. EDI and interfirm relationships: toward a standardization of coordination processes? Information, Economics and Policy 6, 319-47.

Burt, R., 1992. Structural Holes. Cambridge, Harvard University Press.

Christopher, M., 1998. Logistics and Supply Chain Management. London, Pitman Publishing.

Coase, R.H., 1937. The nature of the firm. Economica 4, 386-405.

Coleman, J., 1990. The Foundations of Social Theory. Cambridge, Harvard University Press.

Croom, S.R., 2000. The impact of web-based procurement on the management of operating resources supply. Journal of Supply Chain Management (Winter), 4-12.

Dearing, B., 1995. EDI: driving VAN growth. Telecommunications (June), 69-73.

Demsetz, H., 1988. The theory of the firm revisited. Journal of Law, Economics and Organization 4, 141-62.

Domowitz, I., 1995. Electronic derivatives exchanges: implicit mergers, network externalities, and standardization. Quarterly Review of Economics and Finance 35, 163-75.

Dyer, J.H., 1997. Effective interfirm collaboration: how firms minimize transaction costs and maximize transactional value. Strategic Management Journal 18, 535-56.

Dyer, J.H. and K. Nobeoka, 2000. Creating and managing a knowledge-sharing network: the Toyota case. Strategic Management Journal 21, 345-67.

Dyer, J.H. and H. Singh, 1998. The relational view: cooperative strategy and sources of inter-organisational competitive advantage. Academy of Management Review 23, 660-79.

Economides, N., 1996. The economics of networks. International Journal of Industrial Organization 13, 673-99.

Economist, the. The net imperative: survey on business and the Internet. June 26, 1999.

Fama, E.F. and M.C. Jensen, 1983. Separation of ownership and control. Journal of Law and Economics 26, 301-25.

Farrell, J. and G. Saloner, 1985. Standardization, compatibility, and innovation. Rand Journal of Economics 16 (Spring), 70-83.

Feldman, M.P. and D.B. Audretsch, 1998. Innovation in cities: science-based diversity, specialization and localized competition. Working Paper, The Institute for Development Strategies, Indiana University.

Galaskiewicz, J., 1985. Interorganizational relations. Annual Review of Sociology 11, 281-304. 
Gomes-Casseres, B., 1994. Group versus group: how alliance networks compete. Harvard Business Review (July/August), 62-74.

Grabher, G., 1993. The weakness of strong ties: the lock-in of regional development in the Ruhr area. In Grabher, G. (ed.), The Embedded Firm: on the Socioeconomic of Industrial Networks, London, Rutledge, 255-77.

Granovetter, M., 1973. The strength of weak ties. American Journal of Sociology 78, 1360-80.

Granovetter, M., 1985. Economic action and social structure: the problem of embeddedness. American Journal of Sociology 91, 481-510.

Gulati, R. and M. Gargiulo, 1999. Where do interorganizational networks come from? American Journal of Sociology 104, 1439-93.

Gulati, R. and H. Singh, 1998. The architecture of cooperation: managing coordination costs and appropriation concerns in strategic alliances. Administrative Science Quarterly 43, 781-814.

Hagel III, J. and M. Singer, 1999. Unbundling the corporation. Harvard Business Review (March/April), 133-41.

Handfield, R.B. and E.L. Nichols Jr., 1999. Introduction to Supply Chain Management. Upper Saddle River, Prentice Hall.

Hansmann, H., 1996. The Ownership of Enterprise. Cambridge, The Belknap Press.

Holland, C.P., G. Lockett and I. Blackman, 1992. Planning for electronic data interchange. Strategic Management Journal 13, 539-50.

Holmstrom, B. and P. Milgrom, 1994. The firm as an incentive system. American Economic Review 84, 972-91.

Holmstrom, B. and J. Roberts, 1998. The boundaries of the firm revisited. Journal of Economic Perspectives 4, 73-93.

Jensen, M.C. and W. Meckling, 1976. Theory of the firm: managerial behavior, agency costs and capital structure. Journal of Financial Economics 3, 305-60.

Kahan, M. and M. Klausner, 1997. Standardization and innovation in corporate contracting (or 'the economics of boilerplate'). Virginia Law Review 83, 713-70.

Kalaitzandonakes, N. and B. Bjornson, 1997. Vertical and horizontal coordination in the agribiotechnology industry: evidence and implications. Journal of Agricultural and Applied Economics 29, 129-39.

Kambil, A., P.F. Nunes and D. Wilson, 1999. Transforming the marketspace with all-in-one markets. International Journal of Electronic Commerce 3, 11-28.

Kaplan, S. and M. Sawhney, 2000. E-hubs: the new B2B marketplaces. Harvard Business Review (May-June), 97-103.

Katz, M.L. and C. Shapiro, 1985. Network externalities, competition and compatibility. American Economic Review 75, 424-40.

Kekre, S. and T. Mukhopadhyay, 1992. Impact of electronic data interchange technology on quality improvement and inventory reduction programs: a field study. International Journal of Production Economics 28, 265-82.
Klein, B., R. Crawford and A. Alchian, 1978. Vertical integration, appropriable rents, and the competitive contracting process. Journal of Law and Economics 21, 297-326.

Kogut, B., 2000. The network as knowledge: generative rules and the emergence of structure. Strategic Management Journal 21, 405-25.

Kogut, B. and U. Zander, 1992. Knowledge of the firm, combinative capabilities, and the replication of technology. Organization Science 3, 383-97.

Krackhardt, D., 1992. The strength of strong ties: the importance of philos in organizations. In Nohria, N. and R. G. Eccles, Networks and Organizations, Boston, Harvard University Press, 216-39.

Lane, C. and R. Bachmann, 1996. The social constitution of trust: supplier relations in Britain and Germany. Organization Studies 17, 365-95.

Langfield-Smith, K. and M.R. Greenwood, 1998. Developing cooperative buyer-supplier relationships: a case study of Toyota. Journal of Management Studies 35, 331-53.

Lazzarini, S.G. and J.A. Nickerson, 2000. Modular governance: explaining the impact of information technology on the boundaries of the firm. Working Paper, John M. Olin School of Business, Washington University.

Leonard-Barton, D., 1995. Wellsprings of Knowledge: Building and Sustaining the Sources of Innovation. Boston, Harvard Business School Press.

Levinthal, D.A. and M. Warglien, 1999. Landscape design: designing for local action in complex worlds. Organization Science 10, 342-57.

Madhavan, R., B.R. Koka and J.E. Prescott, 1998. Networks in transition: how industry events (re)shape interfirm relationships. Strategic Management Journal 19, 439-59.

Marcussen, C.H., 1996. The effects of EDI on industrial buyersupplier relationships: a network perspective. Journal of Supply Chain Management 32, 20-26.

McEvily, B. and A. Zaheer, 1999. Bridging ties: a source of firm heterogeneity in competitive capabilities. Strategic Management Journal 20, 1133-56.

Nelson, R.E., 1989. The strength of strong ties: social networks and intergroup conflict in organizations. Academy of Management Journal 32, 377-401.

Nelson, R.R. and S.G. Winter, 1982. An Evolutionary Theory of Economic Change. Cambridge, The Belknap Press.

Niederman, F, 1998. The diffusion of electronic data interchange technology. In Larsen, T.J. and E. McGuire (eds.), Information Systems Innovation and Diffusion: Issues and Directions, Hershey, Idea Group Publishing, 141-60.

Nishiguchi, T., 1994. Strategic Industrial Sourcing: The Japanese Advantage. Oxford, Oxford University Press. 
Nohria, N., 1992. Introduction: is a network perspective a useful way to studying organizations? In Nohria, N. and R.G. Eccles, Networks and Organizations, Boston, Harvard University Press, $1-22$.

Norman, R. and R. Ramirez, 1993. From value chain to value constellation: designing interactive strategy. Harvard Business Review (July-August), 65-77.

Ouchi, W.G., 1980. Markets, bureaucracies and clans. Administrative Science Quarterly 24, 129-41.

Pennings, J.M., 1981. Strategically interdependent organizations. In: Nystrom, P.C. and W.H. Starbuck (eds.), Handbook of Organizational Design, vol. 1, New York, Oxford University Press, 433-55.

Pfeffer, J. and P. Nowak, 1976. Joint ventures and interorganizational interdependence. Administrative Science Quarterly 21, 398-418.

Porter, M.E., 1985. Competitive Advantage. New York, The Free Press.

Powell, W.W., 1990. Neither market nor hierarchy: network forms of organization. Research in Organizational Behavior 12, 295336.

Powell, W.W., K.W. Koput and L. Smith-Doerr, 1996. Interorganizational collaboration and the locus of innovation: networks of learning in biotechnology. Administrative Science Quarterly 41, 116-45.

Rangan, V.K., 1998. FreeMarkets OnLine. Case Study 9-598-109, Harvard Business School.

Rowley, T., D. Behrens and D. Krackhardt, 2000. Redundant governance structures: an analysis of structural and relational embeddedness in the steel and semiconductor industries. Strategic Management Journal 21, 369-86.

Sappington, D., 1991. Incentives in principal-agent relationships. Journal of Economic Perspectives 5, 45-66.

Simchi-Levi, D., P. Kaminski and E. Simchi-Levi, 2000. Designing and Managing the Supply Chain: Concepts, Strategies, and Case Studies. New York, Irwin McGraw-Hill.

Staatz, J.M., 1987. The structural characteristics of farmer cooperatives and their behavioral consequences. In Royer, J. S. (ed.), Cooperative Theory: New Approaches, Service Report 18, Washington, DC: USDA Agricultural Cooperative Service, 33-60.

Stabell, C.B. and O.D. Fjeldstad, 1998. Configuring value for competitive advantage: on chains, shops and networks. Strategic Management Journal 19, 413-37.

Stuart, I., P. Deckert, D. McCutcheon and R. Kunst, 1998. Case study: a leveraged learning network. Sloan Management Review 4, 81-93.

Swaminathan, A., G. Hoetker and W. Mitchell, 2000. Network structure and business survival: the case of U.S. automobile component suppliers. Working Paper.

Teece, D.J., 1986. Profiting from technological innovation: implications for integration, collaboration, licensing and public policy. Research Policy 15, 285-305.
Teece, D.J., 1998. Capturing value from knowledge assets: the new economy, markets for know-how and intangible assets. California Management Review 40, 55-79.

Teece, D.J., G. Pisano and A. Shuen, 1997. Dynamic capabilities and strategic management. Strategic Management Journal 18, 509-33.

Telser, L.G. and H.N. Higginbotham, 1977. Organized futures markets: costs and benefits. Journal of Political Economy 85, 969-1000.

Thompson, J.D., 1967. Organizations in Action: Social Science Bases of Administrative Theory. New York, McGraw-Hill.

Uzzi, B., 1997. Social structure and competition in interfirm networks: the paradox of embeddedness. Administrative Science Quarterly 42, 35-67.

Van de Ven, A.H., A.L. Delbecq and R. Koenig Jr., 1976. Determinants of coordination modes within organizations. American Sociological Review 41, 322-38.

Victor, B. and R.S. Blackburn, 1987. Interdependence: an alternative conceptualization. Academy of Management Review 12, 486-98.

Wada, T. and J.A. Nickerson, 1998. Proprietary information networks and the scope of the firm: the case of international courier and small package services in Japan. In: Crew, M.A. and P.R. Kleidorfer (eds.), Emerging Competition in Postal and Delivery Services, Boston, Kluwer, 123-38.

Wasserman, S. and K. Faust, 1994. Social Network Analysis. Cambridge, Cambridge University Press.

Weick, K. E., 1976. Educational organizations as loosely coupled systems. Administrative Science Quarterly 21, 1-16.

Williamson, O.E., 1985. Economic Institutions of Capitalism. New York, The Free Press.

Zaheer, A. and N. Venkatraman, 1994. Determinants of electronic integration in the insurance industry: an empirical test. Management Science 41, 401-18.

Zajac, E.J. and C.P. Olsen, 1993. From transaction cost to transactional value analysis: implications for the study of interorganizational strategies. Journal of Management Studies 30, 131-45.

Zenger, T. R. and L. Poppo, 1999. A knowledge-based theory of organizational boundaries. Working Paper, John M. Olin School of Business, Washington University.

Zylbersztajn, D., 1996. Governance structures and agribusiness coordination: a transaction cost economics based approach. In Goldberg, R. A. (ed.), Research in Domestic and International Agribusiness Management, vol. 12, Boston, JAI Press, 245-310.

Zylbersztajn, D. and E.M.M.Q. Farina, 1999. Strictly coordinated food systems: exploring the limits of the Coasian firm. International Food and Agribusiness Management Review 2, 249-65. 